Egypt. Acad. J. biolog. Sci., 2 (1): 1- 15(2010)

Email: egyptianacademic@yahoo.com

Received: $29 / 6 / 2010$
E. Medical Entom. \& Parasitology

ISSN: 2090 - 0783

www.eajbs.eg.net

\title{
Species identification and infectivity rate of malaria vector in two endemic malaria areas in Sudan
}

\author{
Tasneem Moawia Abd Allah Osman \\ Department of Zoology, Faculty of Science, University of Khartoum.
}

\begin{abstract}
Attempts were made to identify, Anopheline species by using Polymerase Chain Reaction (PCR) and to determine the sporozoite infection rate in malaria vectors using Enzyme Linked Immunosorbent Assay (ELISA). Samples were collected from highly endemic areas in central Sudan (Sennar), and eastern Sudan (Koka).Morphological Identification was carried using available keys. Anopheles gambiae complex was then identified using PCR. Out of fifty two was identified as Anopheles arabiensis $(92.3 \%)$. The sporozoite infection rate was estimated using ELISA method the infectivity rates were 16\% (4/24), 15\% (3/21) in Sennar and Koka respectively. This data indicated that the two areas are endemic for malaria and $A n$. arabiensis is the main vector in the study areas. The sporozoite infection rate was found to be $16 \%(4 / 24)$ in Sennar samples, whereas it was found to be $15 \%(3 / 21)$ in Koka samples. Thus, data indicate of these two areas are endemic for malaria and An.arabiensis is the main vector in these areas.
\end{abstract}

Keywords: Malaria vector, endemic,Sudan

\section{INTRODUCTION}

Malaria is the most important vector-borne infectious disease in the world, caused by the protozoon Plasmodium and transmitted by the bite of an infected female Anopheles mosquito. Between 300 and 500 million new cases of malaria occur every year, resulting in 1-3 million deaths, mostly among African children under the age of five (Toure' and Oduola, 2004). The development of the parasite resistance to drugs and of the vector resistance to insecticides, as well as the lack of an effective vaccine, emphasizes the need for alternative weapons to fight the disease. The molecular events that guide the parasite life cycle and its interactions with the mosquito remain poorly understood and a better understanding of these issues may lead to the identification of new targets for malaria control. For malaria transmission to occur, the parasite has to undergo a complex developmental programme inside the mosquito (Fig. 1). A small proportion of the parasites circulating in a human host differentiate into male and female gametocytes. Within minutes of ingestion of an infected blood meal by the mosquito, gametocytes differentiate into gametes and emerge from the erythrocytes. The male gametocyte undergoes three rounds of mitosis leading to the formation of eight haploid gametes in a process called exflagellation. Fertilization ensues within one hour and the resulting zygotes gradually differentiate into motile ookinetes. After traversing the peritrophic matrix (PM), which is a chitin-containing extracellular layer surrounding the blood bolus, the ookinetes cross the midgut epithelium and lodge beneath the basal lamina facing the mosquito body cavity (hemocoel). During the next 10-15 days (depending on parasite species 
and temperature) they differentiate into mature oocysts. Each oocyst produces thousands of sporozoites that are released into the hemocoel and invade the salivary glands. When this mosquito takes a blood meal, sporozoites leave with the saliva infecting the new vertebrate host, where the asexual part of the life cycle takes place (Ghosh et al., 2000). Although the asexual blood stages are the best-studied forms of the parasite due to the ease of experimental manipulation, the study of Plasmodium development in the mosquito has been intensified in recent years.

\section{The malaria vector:}

Human malaria can be transmitted only by anopheline mosquitoes. In addition to transmitting malaria, anophelines also transmit filariasis and some arboviral diseases, the genus Anopheles belongs to the order Diptera, sub-order Nematocera, family Culicidae, subfamily Culicinae and tribe anophelini in zoological classification there are 422 species of Anopheles mosquitoes throughout the world, but only some 70 species are vector of malaria under natural condition; of these some 40 species are importance. Natural susceptibility or resistance of Anopheles to infection with a defined species malaria parasite is still only practically understood, although it is certainly related to biochemical processes on the body of mosquito.

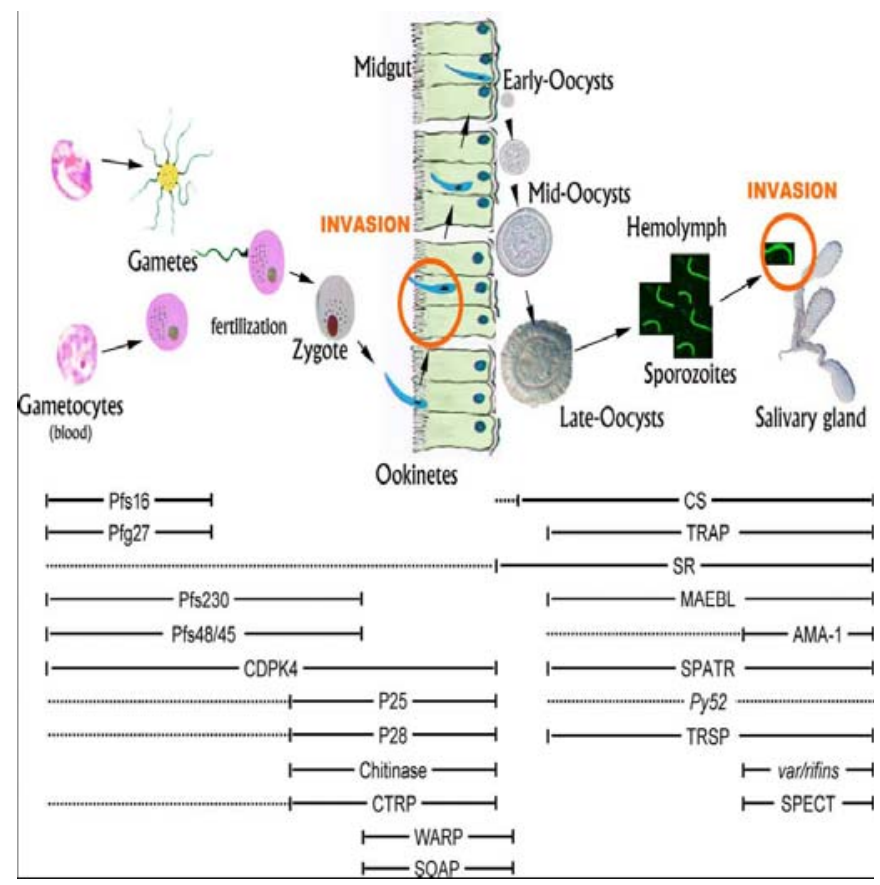

Fig. 1: Plasmodium life cycle and temporal patterns of gene expression. The solid lines indicate parasite stages at which protein was detected, and the dashed lines indicate parasite stages at which mRNA- but not the corresponding protein was- detect. Moreira et al. (2004).

Although Anopheles mosquito are most frequent in tropical or sub tropical regions they are also found in temperate climates and even in the Arctic during summer. As a rule Anopheles are not found at altitudes above 2000-2500m (Service, 1993).
Anophelines are found worldwide except Antarctica. Malaria is and environment.

(www.cdc.gov/malaria/biology/mosqui to/ \#suscepttiblityrefaras ). 
The female mosquito lays her eggs on clean water. Most species use fresh water, though some lay on brackish water. The mosquito goes though four separate and distinct stage of its life cycle (Fig. 2) and they are in follows:

Egg: Eggs are laid one at a time and they float on the surface of the water. In the case of Culex and Culiseta species, the eggs are stuck together in rafts of a hundred or more eggs. Anopheles and Aedes species do not make egg rafts but lay their eggs separately. Culex, Culiseta, and Anopheles lay their eggs on water while Aedes lay their eggs on damp soil that will be flooded by water. Most eggs Mosteggs hatch into larvae within 48 hours.

Larva: The larva lives in the water and come to the surface to breathe. They shed their skin four times growing larger after each molting. Most larvae have siphon tubes for breathing and hang from the water surface. Anopheles larvae do not have a siphon and they lay parallel to the water surface. The larva feed on microorganisms and organic matter in the water. On the fourth molt the larva change in the pupa.

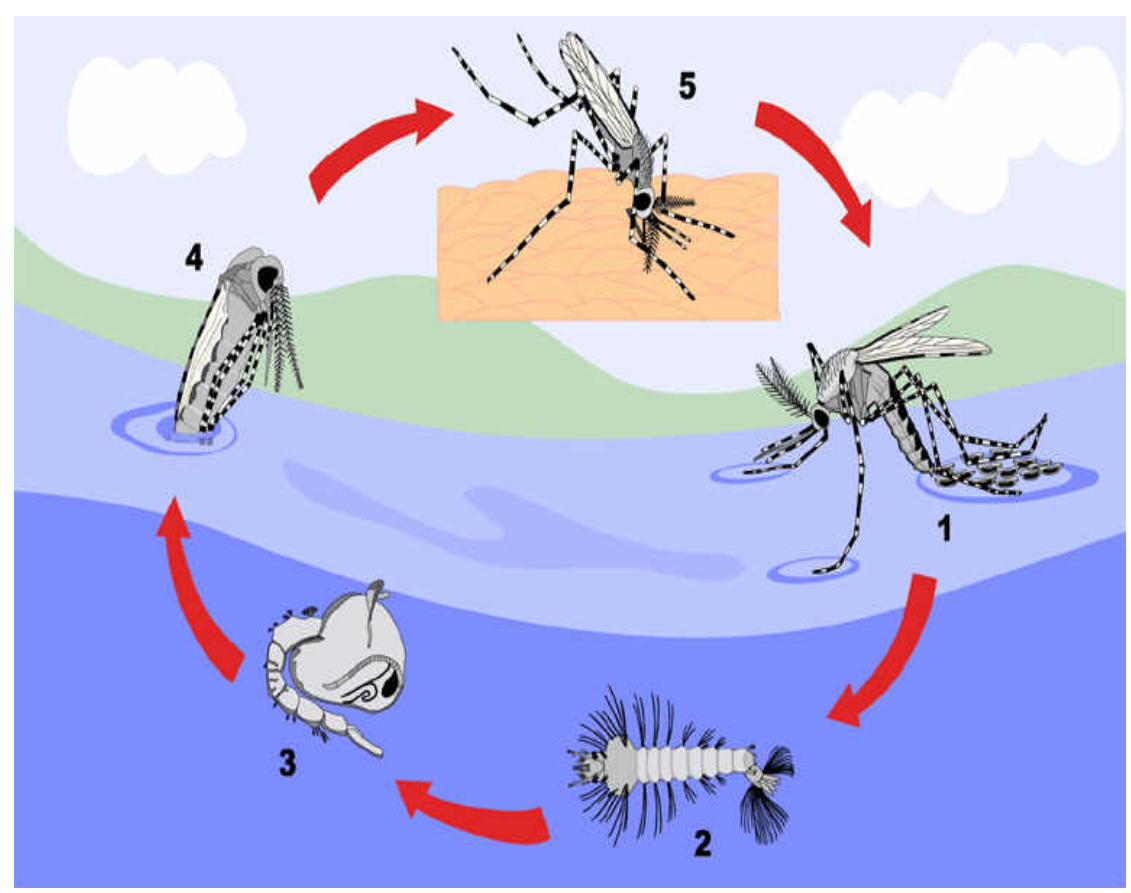

Fig. 2: Malaria vector life cycle; 1.egg, 2.larva, 3.pupae, 4.emergence of adult, 5.adult taking blood meal. (Copyright: Welcome Trust)

(www.cdc.gov/malaria/biology/mosquito/ \#suscepttiblityrefaras).

Pupa: The pupal stage is a resting, non-feeding stage. This is the time the mosquito turns into an adult. It takes about two days before the adult is fully developed. When development is complete, the pupal skin splits and the mosquito emerges as an adult.

Adult: The newly emerged adult rests on the surface of the water for a short time to allow itself to dry and all its parts to harden. Also, the wings have to spread out and dry properly before it can fly. (Service, 1993).

\section{Epidemiology:}

Natural transmission of malaria depends on the present of and relationship between three basic epidemiological factors: the host, the agent and the environment human 
beings are the vertebrate host of human Plasmodia;

The Anopheles mosquito it's the invertebrate host (Gilles, 1993) .The most important cause of epidemic outbreaks is due to a sudden increase of the number of vector, or changes in habits of the mosquito vector or the human host/vector contact (White, 1996). Gender and age are not important factor with regard to the malaria infection, but children have generally a higher degree of susceptibility than adults (Gilles, 1993).

\section{Malaria Seasonality:}

Seasonality in malaria is usually due to fluctuations in environmental conditions (temperature, availability of breeding places and humidity). In tropical countries, the temperature is in favour of mosquito vectors through out the year. However, in these areas, the transmission depends on the availability of the breeding sites, which in turns depends on the annual rainfall patterns (WHO, 2000).

\section{Distribution:}

Plasmodium falciparum is found mainly in the hotter and more humid regions of the world (Fig.3). It's the main species found in tropical and subtropical Africa and part of Central America and South America, Bangladesh, Pakistan, Afghanistan, Nepal, Srilanka, South East Asia, Indonesia, Philippines, Haiti, Solomon Islands, Papua New Guinea and many Islands in Melanesia. Its also occurs in parts of India, the Middle East, eastern Mediterranean and countries of North Africa. (WHO, 2000).

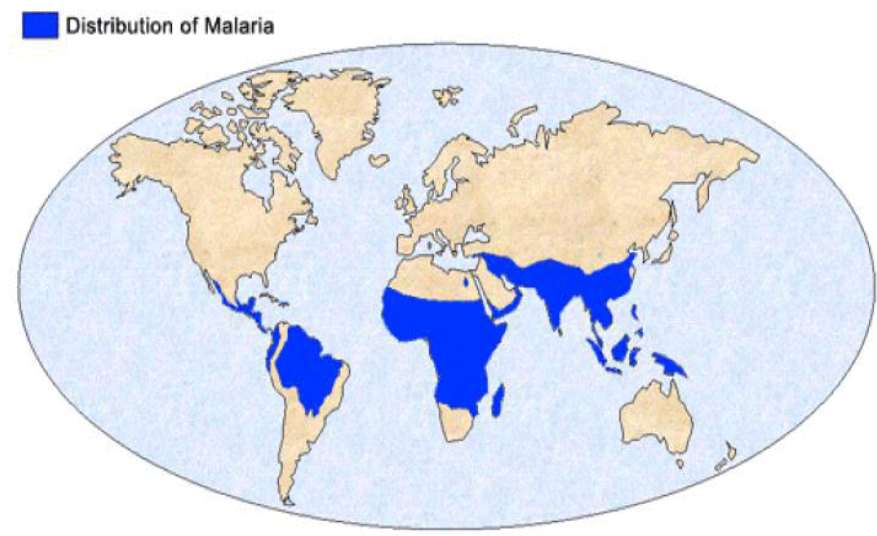

Fig. 3: Worldwide distribution of malaria. (Copyright:CDC) (www.cdc.gov/malaria/biology/mosquito/ \#suscepttiblityrefaras ).

Malaria in Sudan:

Malaria is the major health problem in Sudan, with an estimated 7.5 million morbidity cases occurring annually and more than 35000 deaths, most of these are children and pregnant women. P. falciparum is responsible for about $90 \%$ of malaria cases, in addition to P.malariae and P.vivax (UNICEF/WHO, 2003).
Despite along history of malaria control and eradication (Elgadal et al., 1985), Sudan's cases of malaria constitute half the number of all East Mediterranean Region countries (Malik et al., 2003). This tragic situation is due mainly to environmental degradation, climatic changes and war. The endemicity of malaria varies from hypo-endemic in 
the North to hyper- and holo-endemic in the South.As far as Anopheline mosquitoes are concerned, 31 species were identified from different areas of Sudan.

Of these, 18 species (marked with an asterisk) can be considered as vectors of human malaria, according to the classification of (Hamon and Mouchet, 1961), which was modified by (Gillies and de Meillon, 1968). These country-wide surveys were never repeated again. However, some entomological surveys were later carried out with specific aims e.g. susceptibility testing and cytogenetic studies. These surveys recorded the presence of 11 species in the country; An. arabiensis, An.gambiae, An. funestus, An.nili, An. dthali, An.squamosus, An. rufipes, An. pharoensis, An. pretoriensis, An.coustani, and An.multicolor. (Nugud and Badria, 2001). An. arabienses is the most wide spread member of the An. gambiae complex in Sudan (Dukeen and Omer, 1986). It is highly endophilic except in Khashm el Girba area in East Sudan where the population was found exophilic. It is also highly anthropophilic and it is characterized by a short gonotrophic cycle of a round 48 hours also it has a high probability of daily survival. According to these parameters, An.arabienses was found to have a high vectorial capacity which makes it an efficient malaria vector. . (Nugud and Badria, 2001)

\section{Identification of sibling species:}

Identification of sibling species comprising the An. gambiae complex have been based on crossing experiments (Haridi, 1972; Akiyama, 1973) and cytotaxonomy (Dukeen and Omer, 1986)., showing that An.arabiensis is the most predominant malaria vector in Northern and Central parts of Sudan. In 1962 a group of researchers reported that An.gambiae is a group of sibling species, this encourage researchers to develop new methods to distinguish between these species. These methods, include basic morphology, salinity tolerance, crossmatting experiments and the more recent molecular methods such as PCR.

\section{Morphological Identification:}

Morphological identifications are the baseline of any identification technique. Basic descriptions of anopheline mosquitoes and keys for identification have been established by Gilles and De Mellon (1968) and later improved by Gilles and Coetzee (1987).

Members of the An. gambiae complex are difficult to morphologically identify (Gilles and Coetzee, 1987). Hunt, et. al., (1998) stated that the only reliable morphological characters by which we can differentiate between the two saltwater and the fresh-water species is by using the number of antennal sensillae and the palpal index pointed out by Coluzzi, (1964).

Molecular techniques used for detection of Anopheles species:

Polymerase Chain Reaction:

The polymerase chain reaction (PCR) is an exquisitely, powerful in vitro method for amplifying a defined target DNA sequence. It is new approach for solving problems in molecular genetics, evolutionary and developmental biology, medical diagnosis and forensic medicine. The technique permits a sensitive, selective, accurate, and rapid detection of minute amount of an exact DNA region that lies between two regions of known DNA sequences. It is based on the enzymatic amplify cation of a known, specific DNA fragment using oligonucleotide primers, which specifically attach to the target DNA flanking region. The sequence amplification uses a heat-stable DNA 
polymerase isolated from Thermus aquaticus (Saiki et al., 1988). Oligonucleotide primers are short (1020 nucleotides in length), singlestranded DNA molecules, which are complementary to the ends of a defined sequence of DNA template.The primers are extended on singlestranded denatured template DNA by a DNA polymerase in the presence of deoxynucleoside triphosphates (dNTPs) under suitable reaction conditions. This results in the synthesis of new DNA strands complementary to the template strands. Strand synthesis can be repeated basically by sequential cycles composed of three steps: heat denaturing of the double-stranded DNA at $93-95^{\circ} \mathrm{C}$ to unwind the strand of starting DNA, followed by lowering the temperature of the mixture in the range of $50-60^{\circ} \mathrm{C}$ to allow annealing of primers to the template of singlestranded DNA which target the complementary sequence and finally extension of primers by DNA polymerase at $70-75^{\circ} \mathrm{C}$ which suits the enzyme to complete the reaction (Saiki et al., 1988).

Immunological method:

Enzyme-Linked Immunosorbent Assays (ELISA): ELISA is a widelyused method for measuring the concentration of a particular molecule (e.g., a hormone or drug) in a fluid such as serum or urine. It is also known as enzyme immunoassay or EIA. The molecule is detected by antibodies that have been made against it; that is, for which it is the antigen. Monoclonal antibodies are often used. The test requires the antibodies fixed to a solid surface, such as the inner surface of a test tube a preparation of the same antibodies coupled to an enzyme. This is one (e.g., $\beta$ galactosidase) that produces a coloured product from a colourless substrate. The Test is carried as follows: The tubes are filled with the antigen solution (e.g., urine) to be assayed. Any antigen molecules present bind to the immobilized antibody molecules. The antibody enzyme conjugate is added to the reaction mixture. The antibody part of the conjugate binds to any antigen molecules that were bound previously, creating an antibodyantigen-antibody "sandwich". After washing away any unbound conjugate, the substrate solution is added. After a set interval, the reaction is stopped (e.g., byl $\mathrm{N} \mathrm{NaOH}$ ) and the concentration of colored product formed is measured in a spectrophotometer. The intensity of color is proportional to the concentration of bound antigen. (www.user.rcn.com/jkimball.ma.ultane t/Biology Page/A/AIDS).

Circumsporozoite protein assay (CSELISA): this technique offer several advantages, the main ones being that it is species-specific and can detect sporozoites in pooled samples. (Wirtz et al., 1985) Processing pooled specimens is fast, efficient and economic methods for determining sporozoite prevalence, especially in areas with low malaria endemicity where dissection may not be conducted routinely. (Wirtz et al., 1987; Gu, 1995).

Entomological inoculation rate: The Entomological inoculation rate is the product of the sporozoite rate and the human-biting rate and is the most important and epidemiologically meaningful estimate of human-vector contact. In areas where there are several vector species and in which there are large differences in biting rates and human blood inoculation rate is the most appropriate way in which to establish the relationship between the entomological inoculation rates can be used to determine the entomological impact of an intervention. However, its measurement may not be practical as 
part of routine control activities. (WHO, 1995)

\section{The Role of entomological services in malaria control:}

Entomological expertise is essential for guiding and supporting vector control activities (planning, implementing, monitoring and evaluating vector control). Its contribution depends on objective and targets of malaria control, and available information. For the contribution of entomological services to be cost-effective, their activities must be closely linked with the operational and other epidemiological aspects of malaria control. In malaria control programme that functions properly, entomological services should provide information on: the local vectors (incriminated or suspected), including the members of species complex and their basic biology, temporal and spatial variation in abundance and role in transmission; the biting activity of vector over time and space and their resting behahviour; vector susceptibility to insecticides considers for use; the effect of climatic factors (including seasonal variations in temperture, relative humidity and rainfall) on the breeding and survival of vector; the type and location of vector breeding sites, their contribution to the vector production, and the practicability and relevance of larval control; the efficacy and suitability of control methods at local level.(WHO, 1995).

\section{Study Objectives:}

1. To identify An. arabiensis the main malaria vector species in the study areas using molecular Method (PCR).
2. To determine the sporozoite infection rate in malaria vectors in the study area using Enzyme Linked Immunosorbent Assay (ELISA)

\section{MATERIALS AND METHODS}

\section{Study area:}

This study was carried out in two areas: Koka and Sennar.

\section{Koka village:}

Koka village was established some fourty years ago by the emigrant Hausa tribe from northern Nigeria. Koka village lies about 400 kilometers south-east of Khartoum and about 200 kilometers south-west of Gedarif town in a large mechanized agricultural area in Sudan. The area is endemic for both malaria and visceral leishmaniasis. The Koka community is a closed community, male polygamy and consanguinity is highly practiced.

Sennar:

Sennar state is located in the central-east of Sudan. It Shares its borders with Gezira state in the North, White Nile and upper Nile state in the West, Gadarif state in the east, Blue Nile state and Ethiopia country in the South. It lies also in the rich savanna region between latitude $12.5-14.7 \mathrm{~N}$ and longitude 32.9 - 32.4 S. Summer start in March and end in May, with an average daily temperature $32-40^{\circ} \mathrm{C}$ and relative humidity $25 \%$. The rainy season starts earlier in June and end in September. The temperature raging between $20-25^{\circ} \mathrm{C}$ during winter, which starts in October (Sudan Metrological Services. 2005, unpublished). 

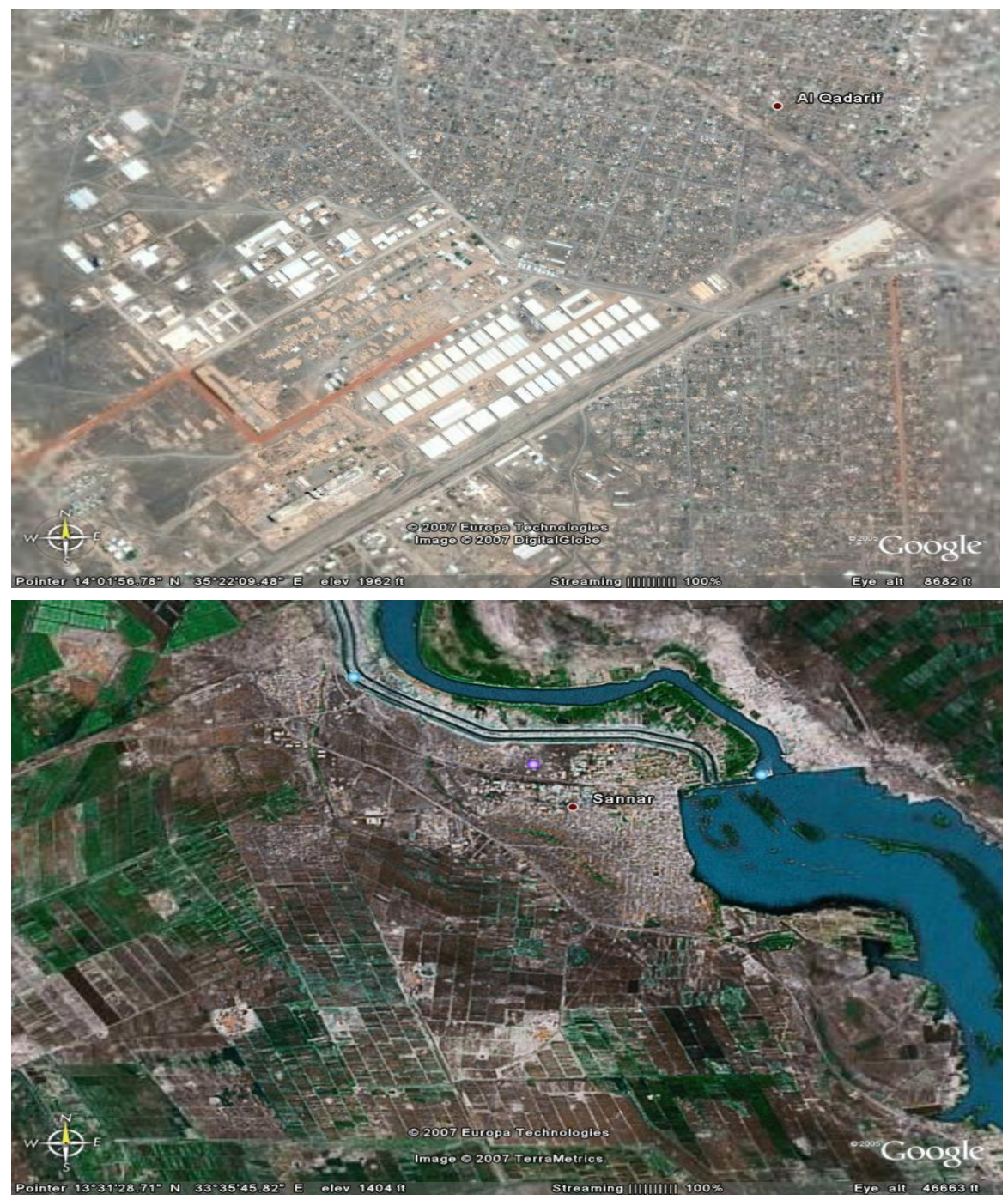

Fig. 4: The google earth map for the study sites

\section{Study Design:}

The study was designed to identify malaria vector and to determine the level of malaria transmission by measuring sporozoite infection rates in the field collected anopheline mosquitoes from the study area.

\section{Mosquitoes collocation (Sampling):}

Adult mosquitoes were collected by knock down spray. The knock down collection was made following the WHO method, using indoors spray catches method (pyrethrum spray collection or PSC).The houses and huts used for this collection where randomly selected in the above mentioned areas taking into consideration that each hut or house is occupied by number of persons with nearby domesticated animals and it is near to one or more breeding sites. In both cases only permantly inhabited hunts where selected. Before spray windows, doors and all opening through which mosquitoes could other wise escape were closed and white cotton sheets were stretched on the floor. The spraying were done in the morning (6 - 9 am). After spraying, the hut was kept close for 10 minutes and then opened for collection. Mosquito were picked up by forceps and placed in Petri-dishes containing moist filter 
paper. All of the collected samples were identified using a microscope. Specimens were then kept dry in eppendorf tube containing silica gel.

Species Morphologic Identification:

Mosquitoes were initially identified according to Abd Elnur (1998a \&b) who used some morphological features, using light microscope . After identification, individual adults were transferred to labeled eppendorf tubes, and the Samples were used later for PCR Identification.

\section{PCR amplification:}

After morphological identification, one Leg from each mosquitoes was placed in $1.0 \mathrm{ml}$ micro-centrifuge PCR tubes, to which was added $12.5 \mu l$ of the PCR master mix containing $10 \mathrm{X}$ PCR buffer (100 Tris-HCl, PH8.3, 500Mm KCl,); 2.5 $m M$ of each dNTP; $25 \mathrm{mM} \mathrm{MgCl} 2 ; 3.3$ $\mathrm{p} / \mathrm{mol}$ of each primer (The primers sequences are shown in table 1), $4.9 \mu 1$ of deionized distilled water and 0.5 uniof thermos table DNA polymerase. The reaction mixture was centrifuged for two minutes at 16,000 revolutions per minute in a microcentrifuge in order to release the template DNA from the tissues, and then the reaction mix was placed in the PCR machine.
The machine was programmed as follows: an initial cycle of denaturizing at $94^{\circ} \mathrm{C}$ for 2 minutes, followed by 30 cycles of denaturizing at $94^{\circ} \mathrm{C}$ for 30 seconds each, annealing at $50^{\circ} \mathrm{C}$ for 30 seconds extension at $72^{\circ} \mathrm{C}$ for 30 seconds and a final extra extension step at $72^{\circ} \mathrm{C}$ for 8 minutes.

\section{Detection of the PCR product:}

Electrophoresis was performed on $7 \mu l$ of the PCR product from each sample was mixed with $3 \mu$ l of loading dye (Ficol dye). Horizontal electrophoresis was done on $1.5 \%$ agarose gel dissolved in $1 \mathrm{X}$ TrisAcetic Acid-EDTA buffer, stained with $1.5 \mu l$ ethidium bromide. $1 \mu l$ from DNA (100bp) marker was used to calculate the average size of the amplified fragment. Electrophoresis was done for $1 \mathrm{~h}$ at $110 \mathrm{~V}$ until Ficol migrated $3 \mathrm{~cm}$ from wells, Culex spp was use as a negative control. Finally, the gel was photographed using gel documentation UVITEC machine. (And the size of the product was confirmed using molecular ladder). The preparation of buffer and gel are shown in Appendix (1) a .The Anopheles gambiae complex primers (Scott et al., 1993) was used in this study is given in the following table:

Table (1): Anopheles gambiae complex species-specific primers

\begin{tabular}{|l|c|c|c|}
\hline $\begin{array}{l}\text { Primer } \\
\text { name }\end{array}$ & Primer sequence (5' to 3') & Sequence base pair & Species \\
\hline UN & GTG TGC CCC TTC CTC GAT GT & & All species \\
\hline AR & AAG TGT CCT TCT CCA TCC TA & 315 & An. Arabiensis \\
\hline
\end{tabular}

\section{CS-ELISA:}

The method described by (Wirtz et al., 1987) was used in this study. The heads and thoraces of the mosquitoes collected were placed individually in labeled vials and each part of the mosquito was ground in $50 \mu l$ of blocking buffer (BB) with
$0.5 \%$ Nonidet P-40, a non ionic detergent (BB: Np-40), $\mathrm{pH} 7.0-7.4$, in a $1.5 \mathrm{ml}$ polypropylene micro-centrifuge tube. After grinding, $150 \mu l$ of BB was added to bring the total of the titrate to $200 \mu l$. Four negative controls (Culex $s p$.) and one positive control were used. 
Each well of a 96-well microtitration plate was coated with $50 \mu \mathrm{l}$ of 1X PBS solution containing the $P$. falciparum and $P$. vivax capture antibodies $(5 \mathrm{ml} \mathrm{PBS} / 40 \mu \mathrm{l}$ Pf2A10 and $5 \mathrm{ml} / 10 \mu \mathrm{l}$ Pv210), covered and incubated overnight at $4{ }^{\circ} \mathrm{C}$. Separate plates was used for each parasite species. The next morning, the contents of the plates were aspirated, each well filled with blocking buffer and incubated at room temperature for one hour. Then, the blocking buffer was aspirated and $50 \mu 1$ of the mosquito triturate was added to the appropriate wells. After incubation for two hours, the mosquito titrate was transferred to the other plate coated with $P$. falciprum capture Mab. The plates were washed twice with PBS-Tw20 solution. Then, $50 \mu 1$ of the horseradish phosphatase labeled Pf2A10 antibody, diluted in blocking buffer, was added to each well. The plates was covered and incubated in a dark place for one hour. The plate then was washed with
PBS-Tw20 three times and $100 \mu$ of peroxidase substrate was added to each well. Finally, absorbance was read at $405 \mathrm{~nm}$ using an ELISA plate reader after half an hour incubation. Each positive sample was retested for confirmation. Samples were considered positive if absorbance exceeds twice the mean of seven negative controls.

\section{RESULTS}

\section{Identified species:}

All collected samples were
shard in main morphological
characteristics which were length of
the maxillary palps, wings spots, legs
shape and the mouth part and
abdominal end model. Indicate that the
studied samples were belonged to the
An. gambiae complex.

By using PCR techniques the majority $92.3 \%(n=52)$ of the mosquito were showed the diagnostic fragment (315) of An. arabiensis. The other 7.7\% of the samples were not identified. (Fig. 5).

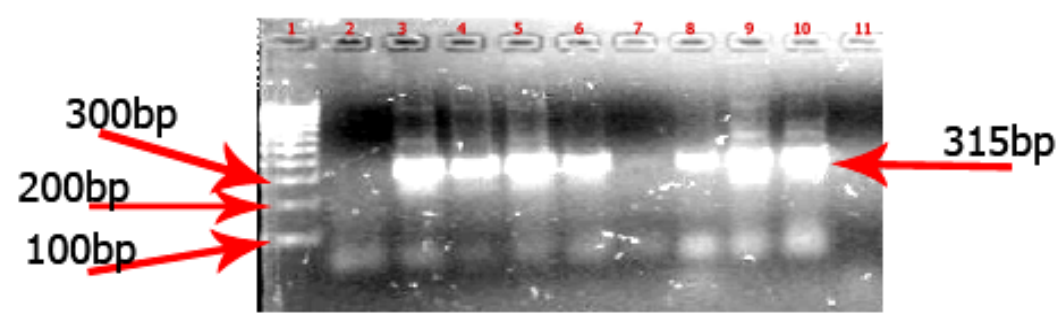

Fig. 5: Amplified fragment using the species-specific PCR assay for the identification of member of the An. gambiae complex. Lane 1 molecular marker; lane 2: negative control; lane 3 positive control; (An.arabiensis) lanes 4to10.

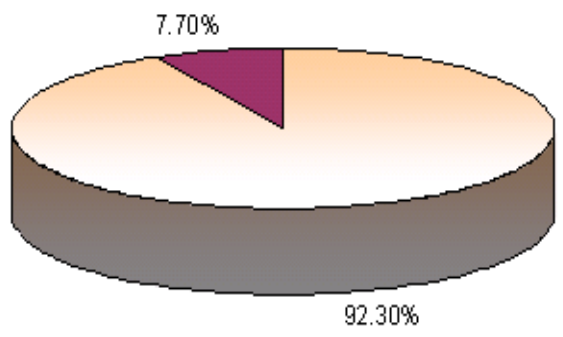

Fig. 6: Percentage of An. Arabiensis in study areas. 


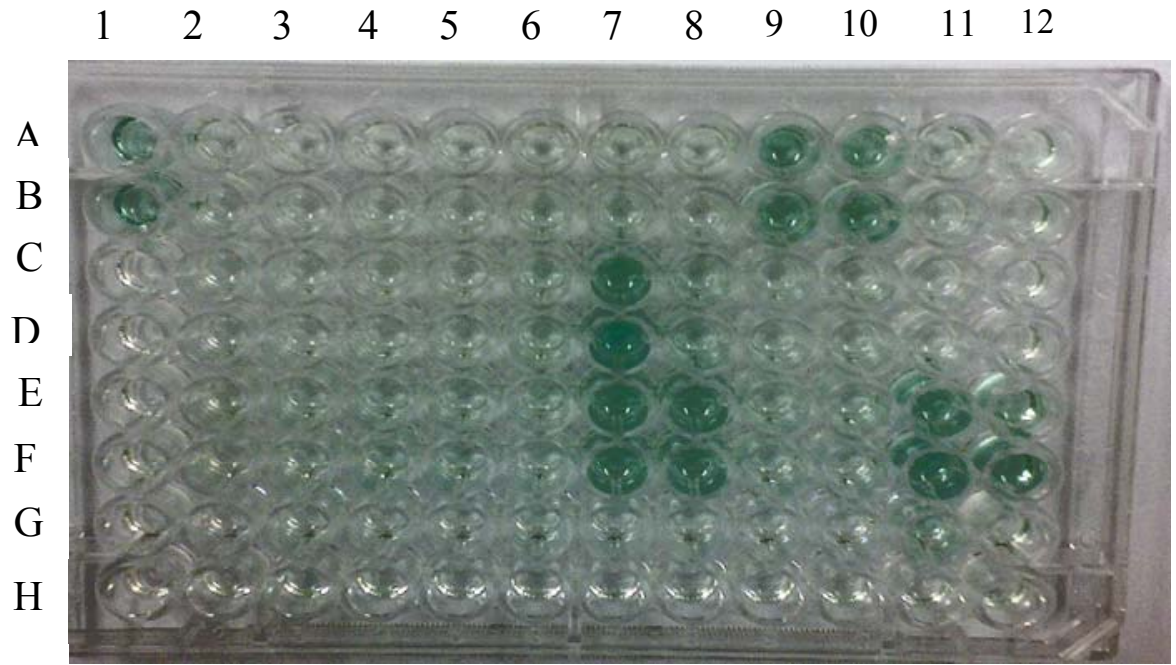

Fig.7: Microtitre plate showing result of ELISA after PCR identification (An. arabiensis). The green color indicates positive results for CS- ELISA. Well A1 and B1 is positive control and C1 to G1 are negative control. Samples showing dark green colors are positive for CSP protein.

\section{Sporozoite Rate:}

P. farciparum sporozoite infections were determined in the 44 knock down collected Anopheles arabiesis mosquitoes using ELISA technique. The highest sporozoite rate of $P$. falciparum was found in Sennar state $16 \%(4 / 24)$, in koka the infection rate was $15 \%(3 / 21)$.

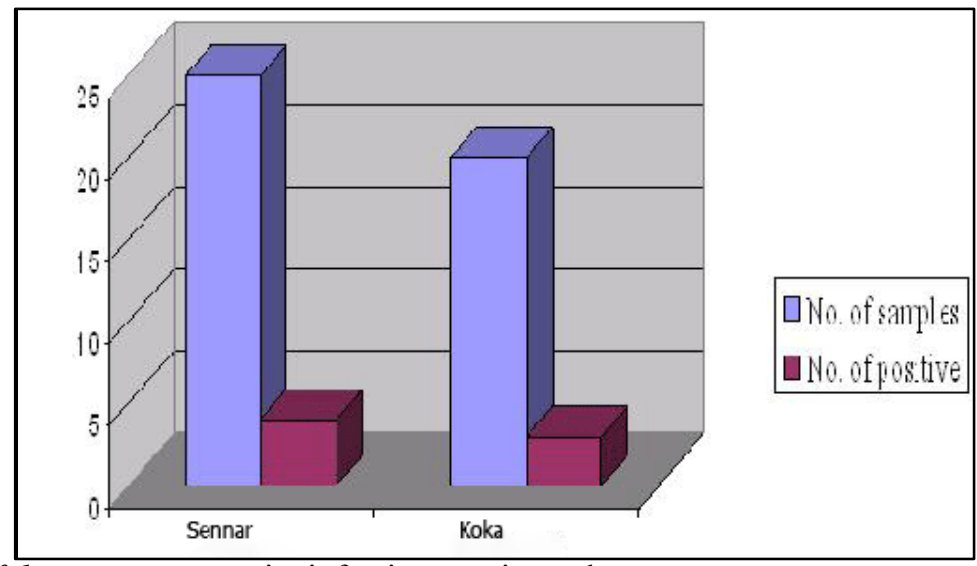

Fig. 8: Results of P. falciparum sporozoite infection rate in study areas.

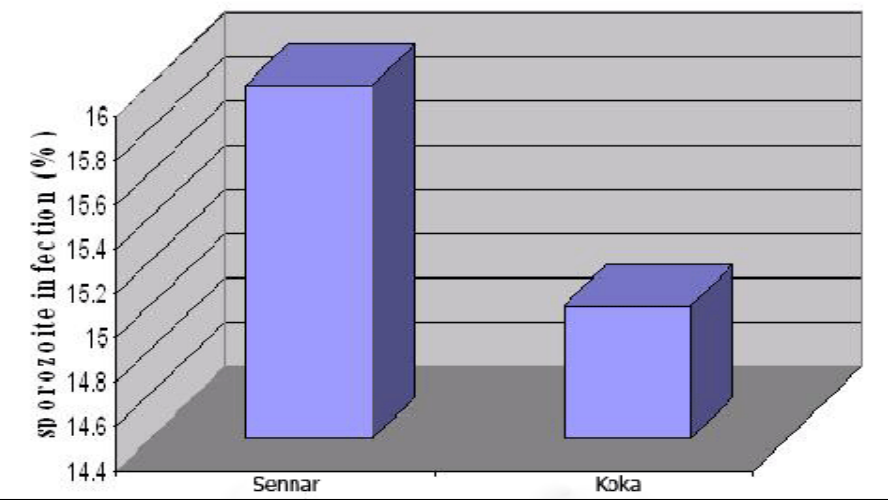

Fig. 9: Results of $P$. falciparum sporozoite infection rate in An. Arabiensis per site. 


\section{DISCUSSION \\ Species identification:}

The most efficient vectors of human malaria in Africa are member of the An. gambiae complex and An. funestus group (Coluzzi et al., 1979; Coetzee et al., 2000).

In Sudan, There are 29 anopheline mosquito species that have so far been recorded (Lewis, 1958).they are widely distributed throughout the country, but more often are localized in the humid areas. An. arabiensis and An. gambiae are the only species of the An. gambiae complex reported in Sudan (Zahar, 1985; Petrarca et al., 2000).

Previous studies carried out in Sennar state indicated that $A n$. arbiensis is the most predominant species in the area (Noor Eldayem, 2005).The only other Anopleline species that have been reported from the study area were An.rufipes Gough and An. pharoensis Theobald, but these two species play no role in malaria transmission because of their largely zoophilic behaviour (Lewis, 1958; El Gadal et al., 1985).

This study presents the first application of the PCR method of Scott et al (1993) on field-collected specimens from Sudan. Out of 60 An.gambiae complex tested, 52 $(92.3 \%)$ were identified as an. arabiensis. The rest $(7.7 \%)$ were not classified due to either misidentification during the morphological method process or DNA degradation due to bad preservation.

These results confirmed that An.arabiensis is the only member of the gambiae complex found in the study areas. The abundance of $A n$. arabinsis in the areas governed by the rainfall, dams and the spread of the irrigation schemes with new irrigation practices which constitute favorable larval habitats (Mouchet et al; 1998; El Gadal et al, 1985).

The advantage of using PCR in mosquito identification is that small part of either fresh or preserved samples could be used. This allows the testing for the presence of the sporozoites with the remaining samples (Paskewitz et al., 1990). Furthermore, the in-necessity of DNA extraction and the availability of using parts of the mosquito (leg, wing, etc) make the method easy and suitable for routine work as 100 samples could be identified in a single day. The only disadvantage of this method is the cost of reagents and equipment needed to perform the job.

Sporozoite analysis:

One of the most important parameters in understanding transmission of malaria vector is the identification of sporozoite infection rate. $P$. falciparum sporozoite infections were determined in the 44 knock down collected An. arabiensis mosquitoes using ELISA technique. The detection of plasmodium sporozoite of human origin in mosquito salivary glands is important to determine the vector status.

The sporozite rate can be used to estimate the sporzoite inoculation rate of the human-biting mosquito population and is key parameter in quantity analysis of natural transmission. Using the conventional method of salivary gland dissection to detect Plasmodium sporozoites is time consuming system, requires appropriate technical skills and need to be carried out using fresh mosquitoes.

The immunodiagnostic technique ELISA, based on monoclonal antibodies to circumsporozoite proteins (CSPs), allows rapid estimation of sporozoite antigen rates and densities in large samples of mosquitoes. The ELISA 
requires laboratory-based facility, higher financial inputs than the dissection method.

The higher positivity rate may be explained by the fact that sample collection were done during the malaria season. Bearing in mind, the sample size of this study is too small, further studies with large sample size are needed in order to accurately determine the sporozoite positivity in the areas.

\section{ACKNOWLEDGEMENT}

I would like to express my thank and gratefulness to my supervisor Dr. Abo Algasim Ibrahim Abd Alhaleem.

Deepest gratitude and sincere thanks are extended to Dr. Ibrahim M. Elhassan, head department of parasitology and Medical Entomology, Insttiue of Endemic Diseases, University of Khartoum. for his supervision and guidance.

\section{LIST OF FIGURES}

Fig. 1: Life cycle for malaria parasites. Fig. 2: Malaria vector life cycle Fig. 3: Map of Worldwide distribution of malaria.

Fig. 4:Map of study areas

Fig. 5: Amplified fragment using the species-specific PCR assay.

Fig. 6: Percentage of An. Arabiensis in study areas.

Fig. 7: Microtitre plate showing result of ELISA

Fig. 8: Results of $P$. falciparum

sporozoite infection rate in study areas.

Fig. 9: Results of $P$. falciparum sporozoite infection rate in $A n$. Arabiensis per site.

\section{REFERENCES}

Akiyama.J, (1973). Exophily in Anopheles gambiae species B in the Sudan Trans. Roy. Soc. Trop. Med. Hyg., 73:440-442.

Coluzzi, M.(1964). Morphological divergences in the Anopheles gambiae . Rivsta di Malariologia, 43:197-232.
Special thanks to Dr. Amna Osman for her continuous help, advice, and support.

My sincere thanks are due to Dr. Heba Salah for her support.

My thanks go also to Dr. Fathe Arrabaa for his advance.

My great thanks to my friends for their encouragement and support.

I would like to thank the staff of the Institute of Endemic Diseases and especially for members of Department of Parasitology and Medical Entomology for their technical help during lab work.

My thanks extended to Mr. Osma Mohamed almakki.

my great thanks and deep appreciation goes to Mr. Yazeed

Words of thanks go to Miss. Amani My great thanks to IESO office for their different services.

\begin{tabular}{ll}
\multicolumn{1}{c}{ LIST OF } & ABBREVIATIONS \\
An & Anopheles \\
CDC & Centers for Disease Control \\
dNTPs & deoxy Nucleoside Triphos \\
Phates & \\
ELISA & Enzyme-Linked \\
Immunosorbent & Assays \\
CSP & Circumsporzoite protein \\
PSC & pyrethrum spray collection \\
PCR & Polymerase chain reaction \\
P & Plasmodium \\
PBS & Phophate Buffered Saline \\
WHO & World Health Organization \\
TBE buffer & Tris Boric EDTA buffer \\
Bp & Base pair
\end{tabular}

Coluzzi,M., Sabtini, A., Petrarca, V. and Di Deco, M.A. (1979).Chromosamal differentiation and adaptation to human environments in the anopheles gambiae complex. Trans. Roy. Soc. Trop. Med. Hyg., 73:483-497. 
Dukeen.M, Omer.S,(1986). Ecology of the malaria vector anopheles arabiensis Patton (Dipetra: Culicidae) by the Nile in northern Sudan. Bull. Ento. Res., 76: 451467.

Elgaddal A.A, Haridi A.M.Hassan, F.Tand Hussein H ,(1985). Malaria control in the Gezira. Manigal irriga Scheme of the Sudan. J.Trop. Med. Hyg., 88: 153-159.

Gilles, H.M. (1993). Epidemiology of malaria In: Bruce. Chwatt's Essential Malariology, $3^{\text {rd }}$ edition, Gilles, H.M and Warrell, D.A. (Editors). London:Edward Arnold,pp:124-164.

Gilles,M.T \& Coetzee, M. (1987). A Supplement to Anophelinae of Africa South of the Sahara. South African Inst. Med. Res., Johannesburg No.55.

Gilles, MT \& De Meillon B, (1968) .The Anophelinae of Africa South of the Sahara (Ethiopian Zoogeographical Region). South African Inst. Med. Res., Johannesburg.No.54.

Ghosh, A., Edwards, M.J., Jacobs-Lorena, M., (2000). The journey of the malaria parasite in the mosquito: hopes for new century. Parasit. Today 16: 196-201.

Greenwood, B. and Mutabingwa, T. (2002). Malaria in 2002. Nature, 415: 670-672.

Hamon,J. and Mouchet,J.(1961).Les vecteurs secondaire du paludime humain en Afique. Med. Trop. 21,643-660.

Hunt, R.H., Coetzee, M.and Fettene, M. (1998).The Anopheles gambiae complex: anew species from Ethiopia. . Trans. Roy. Soc. Trop. Med. Hyg., 92:231-235.

Lewis, D.J.(1958). Some mosquitoes of the Blue Nile valley in the Republic of the Sudan. Bull. World Health Org., 49:133-155.

Nugud, A.D., and Elsayed, B.B .(2001). Malaria and mosquito in Sudan unpublished report.

Mouchet, J., Manguin, S. Sircoulon, J., Laventure, S., Faye. O., Onapa. A. M., Carnevale, P., Julvez, and
Fontenille, D. (1998).Evolution of malaria in Africa for the past 40 years: Impact of climatic and human factors. J. Amer. Mosq. Cont. Assoc., 14(2): 121-130.

Paskewitz, S.M. \& Collins E.H., (1990) .A method to distinguish the Anopheles gambiae complex by the polymerase chain reaction. Amer. J. Trop. Med. Hyg., 49: 520-529.

Petrarca, V., Nugud, A.D., Elkarim Ahmmed, M.A., Haridi, A.M., Di Deco.M.A.and Coluzzi, M. (2000).Cytogenetics of the Anopheles gambiae complex in Sudan.

Saiki, R.K., Celfand, D.H., Stofel, S., Scharf, S.J., Higuchi, R., Horn, G.T., Mullis, K. B. \&Ehrilich, H.A. (1988). Primer directed enzymatic amplification of DNA with a thermos table DNA polymerises. Science, 239: 487491.Republic of the Sudan Federal ministry of Health National Malaria control program, 2003.

Scott, J.A., Brodgon, W.G. \& Collins, F.H. (1993). Identification of single specimens of the Anopheles gambiae complex by polymerase chain reaction. Amer. J. Trop. Med. Hyg., 49:520-529.

Service, M. W. (1993). The Anopheles vector, p: 96-123.In:Essential Malariology $3^{\text {rd }}$ ed. (Gilles and Warrell, eds). London pp.340.

Toure', Y.T., Oduola, A., (2004). TDR, disease watch, malaria. Nat. Rev. 2: 276-277.

White, N.J., (1996).Malaria, In:Mansons Tropical Disease, Chapter 61:1087-1164.Twenteeth edition, WB Sounders company Ltd.London.

W.H.O. (1995). vector control for malaria and other mosquito-borne disease Technical Report Series. 857 Geneva: World Health Organization.

W.H.O. (2000). WHO Expert Committee on Malaria. Technical Report 
Series. 892 Geneva: World Health Organization.

W.H.O.(2003) Africa malaria report 2003. $\mathrm{cdc} / \mathrm{mal} / 2003.1093$.

W.H.O/OMS (2000).Fact sheets.World Malaria Report. (2005). Roll Back Malaria, World Health Org., and UNICEF.

Wirts, R.A., Zavala, R.A., Charoenvit, Y., Campbell, G.H., Burkot, T.R., Schneider, I., Esser, K.M.,
Beavodin, R.L. and Andre, R.G. (1987)comparative testing of Plasmodium falciparum sporozoite monoclonal antibodies for ELISA development. Bull. (WHO), 65: 39-45.

Zahar, A.R. (1985). Vector bionomics in the epidemiology and control of malaria. Part 1. Section ш, (D) East Africa. WHO/VBC/85.3 World Health Org.. Geneva.

\section{ARABIC SUMMARY}

$$
\begin{aligned}
& \text { تحديد أنواع العدوى ومعدل ناقلات مرض الملاريا في منطقتى الملاريا المتوطنة في السودان }
\end{aligned}
$$

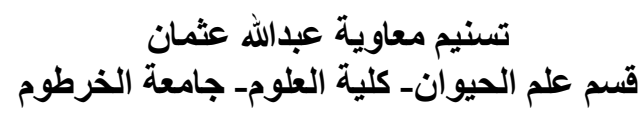

أجريت هذه الدر اسـة لتحديد أنواع الأنوفليه باستخدام تفاعل البلمره المتسلسل حيث تم قيساس معدل

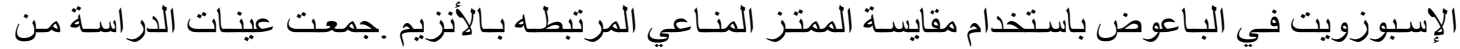

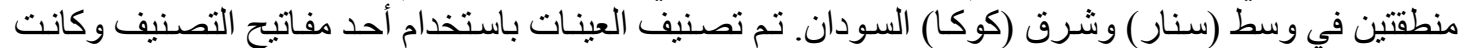

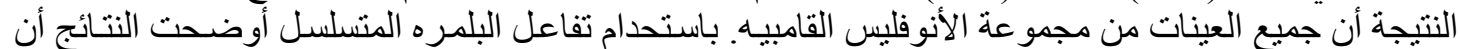

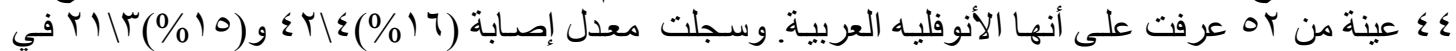

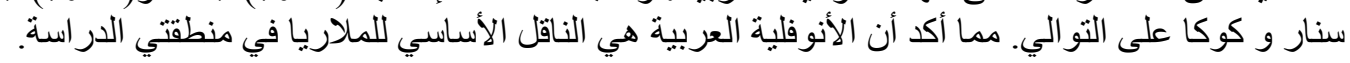

